\title{
Reply: CIITA methylation and decreased levels of HLA-DR in tumour progression
}

\author{
Y Morimoto', M Toyota ${ }^{*, 1}$, H lkeda', T Tokino' and K Imai' \\ 'First Department of Internal Medicine, Sapporo Medical University, S-I, W-I 6, Chuo-ku Sapporo 060-8543, Japan
}

British Journal of Cancer (2004) 91, 8|4-8I5. doi: I0.1038/sj.bjc.6602047 www.bjcancer.com

Published online 27 July 2004

(c) 2004 Cancer Research UK

Sir,

We read with interest the comments and suggestions of Iizuka and Oka regarding our recent report on CIITA methylation in haematopoietic tumour cells (Morimoto et al, 2004). Using DNA microarray analysis of gene expression in hepatocellular carcinoma cells, which was followed by a combinational study using a supervised learning system and statistical analysis, Iizuka et al (2003) were able to isolate 12 genes that appear responsible for early intrahepatic recurrence of cancer after curative resection. One of those genes encoded HLA-DR alpha chain, whose expression was reduced significantly in hepatocellular carcinoma. In a subsequent study, however, they concluded that the respective expression levels of HLA-DR and CIITA were unrelated.

CIITA was originally isolated from a cDNA that restored expression of class II molecules on EBV-B lymphocytes derived from a patient with bare lymphocytes syndrome (Steimle et al, 1993). It is now generally accepted that CIITA is a master activator that regulates class II molecules as well as such class II-associated molecules as invariant chains and HLA-DM (Ting and Trowsdale, 2002). Four distinct promoter units are involved in the transcriptional regulation of CIITA, each transcribing a unique first exon, which is spliced to a common second exon (Muhlethaler-Mottet et al, 1997). Promoters I and III are used for the constitutive expression of CIITA in dendritic cells and B lymphocytes, respectively; the function of promoter II is unknown; and promoter IV controls IFN- $\gamma$-inducible CIITA expression in a variety of cell types. CIITA does not directly bind to MHC class II promoter regions containing cis-acting promoter elements (e.g. W-, X1-, X2- and Y-elements), but appears to exert its effects by trans-activation through protein/protein interactions with components of multiprotein complexes comprising the regulatory factor $\mathrm{X}$ family, which in turn activate transcription factor/cAMPresponsive element binding protein and NF-Y (Ting and Trowsdale, 2002). In a series of studies using knockout mice, CIITA was shown to be essential for the expression of class II molecules and T-cell mediated antigen responses (Chang et al, 1996; Williams et al, 1998). Indeed, transfection of CIITA cDNA into class-II negative cells restores cell surface expression of class II molecules, regardless of cell type (Kanaseki et al, 2003; Morimoto et al, 2004; Takamura et al, 2004). Consequently, at the present time there is

*Correspondence: Dr M Toyota; E-mail: mtoyota@sapmed.ac.jp Published online 27 July 2004 no indication of a discrepancy between the expression of CIITA and that of class II molecules.

Whether comprising solid tumours or haematological malignancies, tumour cells can be classified into three categories based on their expression of class II molecules: (1) those that constitutively express class II molecules even without IFN- $\gamma$; (2) those that will express class II molecules with IFN- $\gamma$; and (3) those that will not express class II molecules even with IFN- $\gamma$. Several groups have investigated the relation between the expression of class II molecules and CIITA in cancers, and their findings indicate that cell type (1) is largely limited to melanoma and glioma (Deffrennes et al, 2001; Takamura et al, 2004) and that most other cancer cells would be classified as either type (2) or (3) (Liu et al, 1999; Soos et al, 2001; Yazawa et al, 2002).

Mechanisms for the inactivation of CIITA are much more complicated, however. Hypermethylation may be a key mechanism by which CIITA promoter activity is silenced in several cancers, as well as in trophoblasts under physiological conditions (van den Elsen et al, 2000; van der Stoep et al, 2002). In addition, we have reported that histone deacetylation, but not hypermethylation, modifies class II transactivator and MHC class II gene expression in squamous cell carcinomas (Kanaseki et al, 2003). In the same vein, we also reported the inactivation of class II transactivation by DNA methylation and histone deacetylation in T-cell and myeloid leukaemia cell lines (Morimoto et al, 2004), and that global histone acetylation in a region $6 \mathrm{~kb}$ upstream of transcriptional start site of CIITA promoter III in glioma cell lines leads to constitutive expression of class II molecules (Takamura et al, 2004). Thus, epigenetic alteration of different CIITA promoters may profoundly influence class II expression in different tissue types. We have not studied hepatocellular carcinomas; however, Sartoris et al (1998) reported successful induction of class II molecules after transfection of CIITA cDNA into a class II negative hepatocellular carcinoma cell line, which suggests that hepatocellular carcinoma may not be exceptional.

As Iizuka and Oka correctly pointed out, we did not investigate the relation between levels of CIITA and HLA-DR and tumour progression. They proposed that we extend our study to relate CIITA methylation with the expression of class II molecules in a larger cohort of haematopoietic tumours. We like this idea, although it clearly goes beyond the primary scope of our investigation.

Finally, we noted with interest the findings of Hippo et al, who analysed global gene expression as Iizuka and Oka did. 
They compared murine scirrhous gastric cancer cells with their highly metastatic derivatives in lymph nodes using the high-density oligonucleotide array method. This enabled them to isolate a cluster of upregulated genes, including MHC class II genes, which were induced via CIITA (Hippo et al, 2001), suggesting that CIITA upregulates class II expression during

\section{REFERENCES}

Chang CH, Guerder S, Hong SC, van Ewijk W, Flavell RA (1996) Mice lacking the MHC class II transactivator (CIITA) show tissue-specific impairment of MHC class II expression. Immunity 4: 167-178

Deffrennes V, Vedrenne J, Stolzenberg MC, Piskurich J, Barbieri G, Ting JP, Charron D, Alcaide-Loridan C (2001) Constitutive expression of MHC class II genes in melanoma cell lines results from the transcription of class II transactivator abnormally initiated from its B cell-specific promoter. J Immunol 167: $98-106$

Hippo Y, Yashiro M, Ishii M, Taniguchi $H$, Tsutsumi S, Hirakawa K, Kodama T, Aburatani H (2001) Differential gene expression profiles of scirrhous gastric cancer cells with high metastatic potential to peritoneum or lymph nodes. Cancer Res 61: 889-895

Iizuka N, Oka M, Yamada-Okabe H, Nishida M, Maeda Y, Mori N, Takao T, Tamesa T, Tangoku A, Tabuchi H, Hamada K, Nakayama H, Ishitsuka H, Miyamoto T, Hirabayashi A, Uchimura S, Hamamoto Y (2003) Oligonucleotide microarray for prediction of early intrahepatic recurrence of hepatocellular carcinoma after curative resection. Lancet 361: 923-929

Kanaseki T, Ikeda H, Takamura Y, Toyota M, Hirohashi Y, Tokino T, Himi T, Sato N (2003) Histone deacetylation, but not hypermethylation, modifies class II transactivator and MHC class II gene expression in squamous cell carcinomas. J Immunol 170: 4980-4985

Liu A, Takahashi M, Toba K, Zheng Z, Hashimoto S, Nikkuni K, Furukawa T, Koike T, Aizawa Y (1999) Regulation of the expression of MHC class I and II by class II transactivator (CIITA) in hematopoietic cells. Hematol Oncol 17: $149-160$

Morimoto Y, Toyota M, Satoh A, Murai M, Mita H, Suzuki H, Takamura Y, Ikeda H, Ishida T, Sato N, Tokino T, Imai K (2004) Inactivation of class II transactivator by DNA methylation and histone deacetylation associated with absence of HLA-DR induction by interferon-gamma in haematopoietic tumour cells. Br J Cancer 90: 844-852

Muhlethaler-Mottet A, Otten LA, Steimle V, Mach B (1997) Expression of MHC class II molecules in different cellular and functional compartments is controlled by differential usage of multiple promoters of the transactivator CIITA. EMBO J 16: $2851-2860$ tumour progression. Moreover, the fact that melanoma and glioma constitutively express class II molecules via CIITA should not be ignored. We thus need to be careful not to draw a simple picture in which only inactivation of CIITA or class II molecules leads to escape from immune surveillance and a poor prognosis.

Sartoris S, Valle MT, Barbaro AL, Tosi G, Cestari T, D'Agostino A, Megiovanni AM, Manca F, Accolla RS (1998) HLA class II expression in uninducible hepatocarcinoma cells after transfection of AIR-1 gene product CIITA: acquisition of antigen processing and presentation capacity. J Immunol 161: 814-820

Soos JM, Krieger JI, Stuve O, King CL, Patarroyo JC, Aldape K, Wosik K, Slavin AJ, Nelson PA, Antel JP, Zamvil SS (2001) Malignant glioma cells use MHC class II transactivator (CIITA) promoters III and IV to direct IFN-gamma-inducible CIITA expression and can function as nonprofessional antigen presenting cells in endocytic processing and CD4(+) T-cell activation. Glia 36: $391-405$

Steimle V, Otten LA, Zufferey M, Mach B (1993) Complementation cloning of an MHC class II transactivator mutated in hereditary MHC class II deficiency (or bare lymphocyte syndrome). Cell 75: 135-146

Takamura Y, Ikeda H, Kanaseki T, Toyota M, Tokino T, Imai K, Houkin K, Sato N (2004) Regulation of MHC class II expression in glioma cells by class II transactivator (CIITA). Glia 45: 392-405

Ting JP, Trowsdale J (2002) Genetic control of MHC class II expression. Cell 109(Suppl): S21 - S33

van den Elsen PJ, van der Stoep N, Vietor HE, Wilson L, van Zutphen M, Gobin SJ (2000) Lack of CIITA expression is central to the absence of antigen presentation functions of trophoblast cells and is caused by methylation of the IFN-gamma inducible promoter (PIV) of CIITA. Hum Immunol 61: 850-862

van der Stoep N, Biesta P, Quinten E, van den Elsen PJ (2002) Lack of IFNgamma-mediated induction of the class II transactivator (CIITA) through promoter methylation is predominantly found in developmental tumor cell lines. Int J Cancer 97: 501-507

Williams GS, Malin M, Vremec D, Chang CH, Boyd R, Benoist C, Mathis D (1998) Mice lacking the transcription factor CIITA - a second look. Int Immunol 10: 1957-1967

Yazawa T, Ito T, Kamma H, Suzuki T, Okudela K, Hayashi H, Horiguchi H, Ogata T, Mitsui H, Ikeda M, Kitamura H (2002) Complicated mechanisms of class II transactivator transcription deficiency in small cell lung cancer and neuroblastoma. Am J Pathol 161: 291-300 